\title{
ИЗУЧЕНИЕ КОРРЕКТНОСТИ ОПРЕДЕЛЕНИЯ ИНТЕРВАЛЫНЫХ ВРЕМЕН ЦЕЛЕВЫХ ВОЛН НА МНОГОКАНАЛЬНОЙ АППАРАТУРЕ АКУСТИЧЕСКОГО КАРОТАЖА.
}

Стенин A.B.

(СК «ПетроАльянс»)

Появление многоканальных акустических зондов позволило повысить точность традиционных для метода акустического каротажа измерений кинематических характеристик волн разных типов, и дало средство изучения целого ряда параметров позволяющих оптимизировать процесс разработки месторождений, контролировать гидроразрыв и т.д.

Изучение корректности отределения интервальных времён проводилось на модельных (лучевое моделирование волновых полей в рамках симметричного ствола скважины) волновых полях $c$ последующим подтверждением реальным материалом. Были исследованы 4 способа расчета интервальных времён (с оценкой устойчивости алгоритмов к случайному шуму) для различной по канальности аппаратуры:

1. Многоканальная деконволюция.

Высокоразрешающий способ оценки интервальных времён на интервале $0.1524 \mathrm{~m}$, с последующей статистической обработкой данных.

2. Спектр медленности

Производился анализ волновых форм для определения когерентных приходов волн, с последующим уточнением в меньшем окне анализа.

3. Определение интервального времени на базе приема (медиана).

Определение интервального времени путём подбора линейной аппроксимации по первым вступлениям целевых волн методом наименьших квадратов, с последующим исключением (после медианирования соседних измерений) точек, отстоящих больше чем на $10 \%$ с последуюшим перерасчетом.

4. Определение интервального времени на базе приема (среднее)

Определение интервального временя путём построения прямой по первым вступлениям целевых волн методом наименьших квадратов.

На рисунке 1 представлена зависимость коэффициента корреляции заданной и полученной скорости в зависимости от отношения сигнал/шума по описанным выше методам расчета интервального времених

Целью работы было нахождение оптимального, с точки зрения разрешағошей способности и точности, алгоритма восстановления заданной скоростной модели.

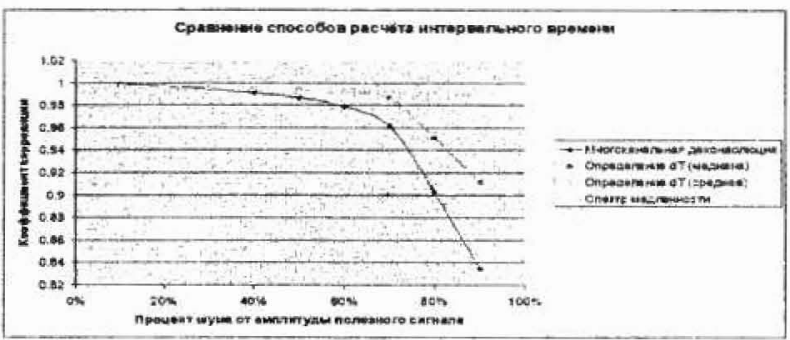

Рис. 1 Сравнение способов расчёта интервального времени.
На рисунке 2 представлены графики 13-и, 8-и, 2-х канальной аппаратуры (Взяты отдельные каналы 8-и канального зонда, база $0.5 \mathrm{M}$ ). Из рисунка 2 видно, что 2-х зондовая аппаратура уже при амплитуде шума более 50 процентов от сигнала имеет коэффициент корреляции ниже 0.5 , кроме того, кривые разных зондов перестают друг друга повторять.

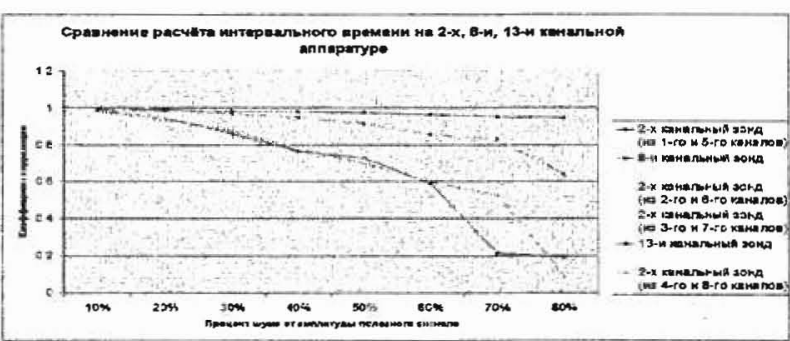

Рис. 2 Сравнение расчёта интервального времени на 2-x, 8-и, 13-и канатьной аптаратуре.

Выводы: По результатам исследований стало ясно, что наиболее стабильньй, малочувствительный к небольшим ошибкам определения первого вступления - является алгоритм расцёта интервального времени на базе приёма (медиана).

Определение интервальньх времён, особенно низкочастотного сигнала (волны Лэмба-Стоунли), 2х зондовыми приборами, при наличии шума от $50 \%$ и выше, несёт в себе большую неисправимую ошибку, по сравнению с многоканальными системами. По разрешающей способности, было выяснено, что большие по своим физическим размерам многоканальные зонды имеют худшгю разрешающую способность на тонких (порядка 0.5м) пластах, однако это может компенсироваться расчётом интервального времени по алгоритму многоканальной деконволюции. Таким образом многоканатьные системы дают значительное улучшение точности расчёта интервального времени. 